\title{
State-of-the-Art and Future Prospects of Canine STR-Based Genotyping
}

\author{
Barbara van Asch $^{1,2, *}$ and Filipe Pereira ${ }^{1}$ \\ ${ }^{1}$ Instituto de Patologia e Imunologia da Universidade do Porto (IPATIMUP), Rua Dr. Roberto Frias s/n, 4200-465 \\ Porto, Portugal \\ ${ }^{2}$ Faculdade de Ciências da Universidade do Porto, Rua do Campo Alegre s/n, 4169-007 Porto, Portugal
}

\begin{abstract}
The dog is the most common domestic animal in human environments and in many situations a dog may be a victim, a perpetrator or a link between a suspect and a crime scene. Therefore, biological material derived from dogs may constitute evidence in forensic caseworks and it may be necessary or helpful to obtain genetic profiles that would aid individual identification. Currently, the assessment of the genetic diversity of breeds, population structure, inbreeding, and the development of methodologies for population assignment are important areas of research in dogs and related species such as the grey wolf. Therefore, canine short tandem repeat (STR)-based genotyping is used by a significant number of population geneticists; however, for reasons we present here, it is utilized by a relatively small number of forensic practitioners. An extensive bibliographic search revealed a highly fragmented canine genotyping community working under less than well defined standards. In this work, we discuss the present developments and limitations of STR-based canine genotyping. Furthermore, we recommend that a collaborative strategy for the implementation of standardization and harmonization is crucial to the development of forensic canine genotyping.
\end{abstract}

Keywords: Canis lupus familiaris, non-human genotyping, short tandem repeat.

\section{BRIEF HISTORY}

The $\operatorname{dog}$ (Canis lupus familiaris) is widely recognized as the most common pet in North American and European households. Despite the constant presence of dogs in human environments, canine derived evidence is not frequently analyzed in forensic caseworks and, consequently, is seldom reported in the literature [1-9]. Numerous situations may occur in which canine genetic identification constitutes an important or even the only source of evidence. Animals can be victims of cruelty and theft; therefore the identification of the remains of a lost or a stolen dog may have to be performed. Also, animals can be perpetrators of a crime, and it may be necessary to identify an animal involved in an attack on a person or other animal. Furthermore, an unrestrained animal may cause an accident or be responsible for property damage. Moreover, animals can also be regarded as "silent witnesses": the analysis of animal DNA transferred as hair, saliva, blood, urine, or feces may provide a link between a suspect to a crime scene or to a victim. Requests of individual profiles, identification for dog paternity investigation and breed registries are growing in demand, as shown by the increasing number of commercial laboratories worldwide that now offer those services.

The development of polymerase chain reaction (PCR) in the late 1980's facilitated the analysis of polymorphic sequences ubiquitously distributed throughout genomes; particularly, tandem repeated units of one to five bp known

*Address correspondence to this author at the IPATIMUP, Rua Dr. Roberto Frias s/n, 4200-465 Porto, Portugal; Tel: +351225570700;

Fax: +351225570799; E-mail: basch@ipatimup.pt as short tandem repeats (STR) or microsatellites were able to be analyzed. STR are highly utilized in forensics, population genetics, molecular ecology and related areas because of their relatively straightforward analysis, especially due to the widespread use of capillary electrophoresis. Human populations have been extensively surveyed via STR-based methodologies over the last 15 years, particularly after the establishment of validated STR panels and databases such as the CODIS (Combined DNA Index System, www.fbi.gov). Isolation and description of canine STRs began in the early 1990 's $[10,11]$ and the physical and linkage mapping of the dog genome have become a major source of mapped loci (e. g. [12-18]). Francisco and colleagues pioneered the mapping of a set of highly polymorphic tetranucleotide loci in 1996; however, other studies mostly reported the mapping of dinucleotide loci. In 1994 Zajc and colleagues [19] first proposed a method of paternity testing in dogs based on microsatellite sequences, followed by similar works in subsequent years (e. g. [20-25]). These early studies attempted to obtain insights into population genetics and phylogenetic relationships between extant and extinct canine populations using STRs originally isolated from the dog genome. The list of investigated species included the Ethiopian wolf [26], the red wolf [27], the red fox [28], the Arctic fox [29] and the grey wolf [30].

Canine genotyping has been particularly performed in non-forensic fields in order to characterize the genetic structure and the diversity within and among dog breeds and wolf populations (e. g. [31-43]). The majority of these studies were motivated by conservation concerns and tried to assess population structure, genetic diversity and inbreeding in endangered populations or small breeds (e. g. [30, 44-58]). As 
natural populations become increasingly threatened by species introduction and the relative abundance of sympatric species, several authors have also discussed the potential hybridization among closely related species, such as the grey wolf, the red wolf, the coyote, and the dog [59-67]. Population assignment based on individual genotypes is becoming an interesting challenge, with a number of researchers using their data to estimate the probability of an individual belonging to a given reference breed or group (e. g. [42, 53, 56, 58, $63,68-74])$. In the literature, two other interesting examples of canine genotyping were mentioned: the establishment of the clonal origin and evolution of a canine transmissible venereal cancer $[75,76]$, and the analysis of a putative dog clone as an independent test to determine the validity of cloned cell lines [77].

DNA quantification is an important step in STR-based analysis prior to conducting PCR, especially in less than pristine sample. This issue was addressed by Evans and colleagues [78], who proposed a real-time PCR assay targeting the canine-specific coding region of the Melanocortin-1 receptor $(M C 1 R)$ gene. They report the successful incorporated of this method into routine analysis of canine biological material.

\section{A DIFFICULT COMING OF AGE}

As presented in the previous section, canine STR-based genotyping has been performed in a wide range of studies for at least 15 years. In order to assess the use of STR markers, we surveyed the literature reporting canine genotyping data between 1996 and 2009 (72 publications) regardless of the objectives of the work (e.g. forensic and non-forensic), from which references to a total of 345 loci were compiled.

A highly dispersed use of STR markers was strikingly evident, as the majority (56\%) were used in a single study, $36 \%$ in 2 to 6 studies, and only $8 \%$ (29 loci) were used in 7 to 27 studies (Fig. 1). Furthermore, a high proportion $(35 \%)$ of the most commonly used 29 markers (Table 1) consisted of dimeric loci. This type of marker is known to have significant germinal and somatic instability, and generates a high amount of stuttering products that are difficult to interpret [79]. For these reasons, dimeric STRs are absent from the international panels for human identification [80], whereas tetrameric loci that have negligible slippage and easy resolution of consecutive alleles are the repeat type of election.

Moreover, it was observed in the literature that genotyping results are generally published in a non-standardized manner due to the lack of a repeat-based nomenclature of alleles (and sometimes even a consistent nomenclature of loci). Recently, a small number of studies [6, 81-84] have discussed this issue and fully characterized some markers as a pre-requisite for routine applications. These studies represent individual in-house efforts to produce suitable panels of

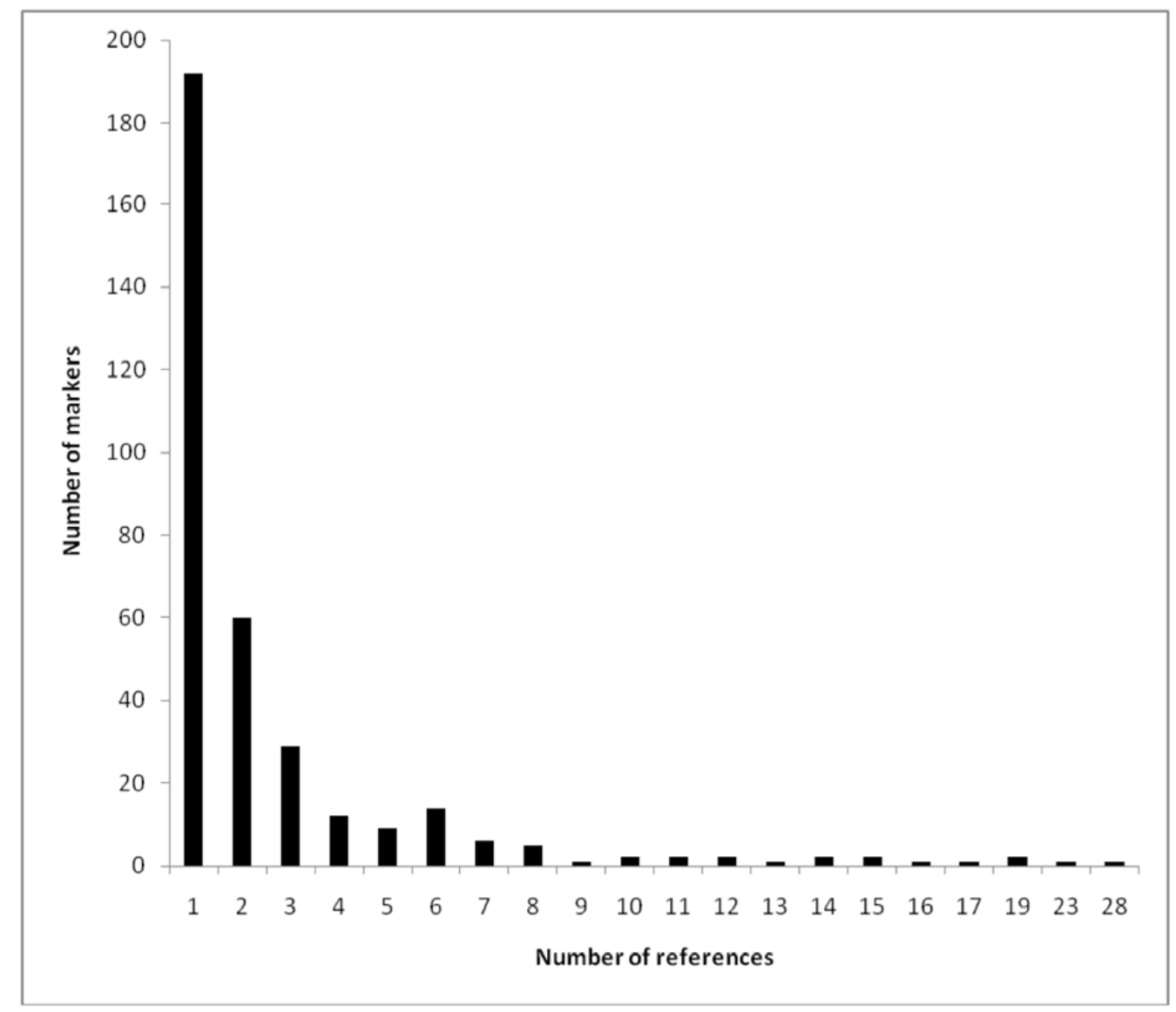

Fig. (1). Number of canine STR markers referenced in published studies. The distribution is based on a total of 345 loci referred in a total of 72 publications. 
Table 1. List of Commonly Used Markers Referred in 7 to 28 Studies Compiled from a Bibliographic Survey Including 72 Publications. Repeat Type, and Availability in at Least One Study of Allele Frequencies and Estimates of Forensic Parameters

\begin{tabular}{|c|c|c|c|c|}
\hline $\mathrm{C} 09.250$ & Dimeric & YES & NO & {$[34,36,37,49,52,58,60,61]$} \\
\hline $\mathrm{CPH} 03$ & Dimeric & YES & NO & {$[34-37,52,60,61,63,71]$} \\
\hline $\mathrm{CPH} 07$ & Dimeric & YES & NO & {$[49,52,59-61,63,71]$} \\
\hline СPH08 & Dimeric & YES & NO & {$[23,34-37,49,51,52,60,61]$} \\
\hline CXX.109/u 109 & Dimeric & YES & NO & {$[30,40,43,48,51,58,66,72]$} \\
\hline CXX.213/u213 & Dimeric & YES & NO & {$[30,49,51,52,60-62,66]$} \\
\hline FH2001 & Tetrameric & YES & YES & {$[22,34-37,43,46,51,54,57,58,62,67,68,70,71,73]$} \\
\hline FH2004* & Tetrameric & YES & YES & {$[22,23,33,34,36,37,46,48,57,63,67,68,73,74,81]$} \\
\hline FH2010* & Tetrameric & YES & YES & $\begin{array}{l}{[3,4,6,7,9,23-25,43,48,50,52,57,58,60-62,67,70,} \\
71,73,74,81,83,84]\end{array}$ \\
\hline FH2017 & Tetrameric & YES & YES & {$[40,43,48,62,63,70,73]$} \\
\hline FH2054* & Tetrameric & YES & YES & $\begin{array}{l}{[3,4,6,7,9,22-25,33-37,41-43,46,48,50,51,57,58,62,} \\
64,67,68,70,71,83,84]\end{array}$ \\
\hline FH2079* & Tetrameric & YES & YES & {$[3,6,7,9,24,25,34,48-50,60-62,67,83,84]$} \\
\hline PEZ03* & Tetrameric & YES & YES & {$[3,6,7,24,25,34,38,43,48,51,62,72,82]$} \\
\hline PEZ05 & Tetrameric & YES & YES & {$[3,4,6,7,24,25,34,40,43,48,50,51,57,62,70,72,73]$} \\
\hline PEZ06* & Tetrameric & YES & YES & {$[3,6,7,9,24,25,48,50,62,83,84]$} \\
\hline PEZ08* & Tetrameric & YES & YES & {$[3,6,7,24,25,34,36,37,43,50,57,58,62,70,82]$} \\
\hline PEZ12* & Tetrameric & YES & YES & {$[3,6,7,9,24,25,34,38,40,43,48,50,57,62,83,84]$} \\
\hline PEZ15* & Tetrameric & YES & YES & {$[7,9,24,25,50,57,83,84]$} \\
\hline PEZ20* & Tetrameric & YES & YES & {$[3,4,6,7,24,25,48,50,62]$} \\
\hline VWF.X* & Hexameric & YES & YES & {$[9,30,43,48,51,52,60-62,70,72,73,83,84]$} \\
\hline
\end{tabular}

*Markers characterized with respect to sequence structure (see also Table 2).

markers for identity and kinship analysis, and have proposed repeat-based nomenclatures for a total of 29 loci (Table 2). In the majority of cases, these descriptions were accompanied by estimates of forensic parameters for identification and parentage testing based on population data. Neverthe- less, data comparison remains generally difficult, if not impossible, because most publications are prior to the studies that presented a standardized repeat-based nomenclature of alleles. 
Table 2. List of Canine STR Loci Characterized at Sequence Level with a Published Repeat-Based Allele Nomenclature. Type of Repeat, Availability of Allele Frequencies and Estimation of Forensic Parameters, and Works where these Markers were used are also Indicated

\begin{tabular}{|c|c|c|c|c|c|}
\hline $\mathrm{C} 38$ & Tetrameric & [81] & YES & YES & {$[74]^{*}$} \\
\hline FH2004 & Tetrameric & [81] & YES & YES & {$[22,23,33,34,36,37,46,57,63,6873,74]^{*}$} \\
\hline FH2054 & Tetrameric & [84] & YES & YES & {$[3,6,22-25,33-37,46,48,50,51,57,58,62,64,68,7042,43,71,83]$} \\
\hline FH2079 & Tetrameric & [84] & YES & YES & {$[3,6,24,25,34,48-50,52,6243,60,61,63,70,83]$} \\
\hline FH2087Ua & Tetrameric & [84] & YES & YES & {$[83]^{*}$} \\
\hline FH2161 & Tetrameric & [82] & NO & NO & {$[34,63,71]$} \\
\hline FH2328 & Tetrameric & [82] & NO & NO & {$[34,73]$} \\
\hline FH2361 & Tetrameric & [81] & YES & YES & {$[34,73,74]^{*}$} \\
\hline FH2611 & Tetrameric & [84] & YES & YES & {$[57,5883]^{*}$} \\
\hline FH2658 & Tetrameric & [81] & YES & YES & {$[57,74]^{*}$} \\
\hline FH3210 & Tetrameric & [81] & YES & YES & {$[74]^{*}$} \\
\hline FH3241 & Tetrameric & [81] & YES & YES & {$[74]^{*}$} \\
\hline PEZ08 & Tetrameric & [82] & NO & NO & {$[3,6,24,25,34,36,37,43,50,57,58,62,70]$} \\
\hline PEZ10 & Tetrameric & [82] & NO & NO & {$[24,25,34,50]$} \\
\hline PEZ12 & Tetrameric & [84] & YES & YES & {$[3,6,24,25,34,38,40,48,50,5762,83 * 43]$} \\
\hline PEZ15 & Tetrameric & {$[84]$} & YES & YES & {$[24,25,50,5783]^{*}$} \\
\hline PEZ20 & Tetrameric & {$[6]$} & YES & YES & {$[3,24,25,48,50,62]$} \\
\hline REN214L11 & Tetrameric & {$[81]$} & YES & YES & {$[74]^{*}$} \\
\hline VWF.X & Hexameric & [84] & YES & YES & {$[30,40,48,51,52,60-62,70,72,73,83 * 43]$} \\
\hline Wilms-T & Tetrameric & [84] & YES & YES & {$[34,83]^{*}$} \\
\hline ZUBECA4 & Tetrameric & [84] & YES & YES & {$[83]^{*}$} \\
\hline ZUBECA6 & Tetrameric & [84] & YES & YES & {$[83]^{*}$} \\
\hline
\end{tabular}


The extremely low number of fully characterized loci in common use (FH2004, FH2010, FH2054, FH2079, FH2132, PEZ03, PEZ06, PEZ08, PEZ12, PEZ15, PEZ20 and VWF.X) may be explained by the fact that most researchers performing canine genotyping are not forensic practitioners. Therefore, these researchers are not under pressure to comply with forensic standards or to contribute to universal databases that allow for inter-laboratory comparisons. Also, and in contrast with the commercial availability of validated human genotyping systems, commercial canine genotyping systems are, at present, inexistent. Despite the value that an STR multiplex kit would bring to the canine genotyping community (forensic and non-forensic), a single commercial kit (Stockmarks ${ }^{\circledR}$ for Dogs Canine Genotyping Kit, Applied Biosystems, Foster City, CA) that was briefly available was subsequently discontinued in 2005. This kit did not include an allelic ladder nor was a nomenclature of the included markers ever published; therefore it is not surprising that the commercial success of the product was greatly compromised from the very beginning. A more convenient product has not become commercially available, further promoting the production of internal laboratory solutions. Although this activity is healthy by principle and has originated useful tools, we have most likely reached a point where greater benefits can only be achieved through broader collaborations.

\section{FUTURE PROSPECTS}

At present, the use of canine STRs is highly fragmented among laboratories, and lacks standardization and harmonization. This is probably the most important reason for the limited use of STR analysis derived from canine evidence in forensic caseworks. Regrettably, we must agree that the forensic laboratories that are used to perform high standard identification and kinship analysis in humans have justifiable reasons to be reluctant. Forensic laboratories rely on validated STR panels, great amounts of comparable population data and well-defined statistical aids to interpret of the results of human analysis, and are therefore generally unwilling to venture onto shakier grounds.

Recently, Kanthaswamy and colleagues [73] selected 18 markers from existing panels in order to assemble a standardized and validated [85] canine forensics panel that will be commercialized in the future by Finnzymes Oy (Espo, Finland) under the designation Canine 2.1 STR Multiplex Reagent Kit. They also have established a database of canine STR genotypes in an updatable format to allow for the inclusion of new data submitted by laboratories that will use this panel. If it proves to be adequate, this kit may constitute an practical tool for the laboratories that wish to implement canine STR analysis.

Regardless of the species under examination, STRs constitute a powerful tool that can be used for identity and kinship testing. The biological principles and the theories, methodologies and technologies are well established for human testing and may only require slight adaptations for nonhuman testing. Basically, a proficient forensic practitioner is equally competent to analyze either human or animal biological evidence. Potentially motivated by the asymmetry of the standards for human genotyping when compared to nonhuman genotyping, Budowle and colleagues, in 2005 [86], proposed the first set of guidelines to inspire quality prac- tices that withstand legal scrutiny for animal genetic identity testing was proposed by in a condensed yet detailed report that is well worth consulting.

Two decades of collective experience in human STRbased genotyping has enabled us to identify the primary issues for the efficient development of non-human genotyping systems. Specifically, it is essential to determine which markers should be used and how to apply them. For the sake of simplicity, the main criteria to consider when selecting suitable STR markers for forensic genotyping may be summarized in the following points: absence of genetic linkage, tetrameric loci (preferably in perfect repeat structures), high level of informativeness, low occurrence of mutations and null alleles, specificity and absence of stutter peaks, and balanced PCR amplification in multiplex reactions. The following points summarize actions necessary for the development of forensic canine genotyping: selection of core STR loci for canine identity testing and establishment of multiplexed panels, development of an internationally recognized allele nomenclature based on the number of repeats determined by sequencing of frequent alleles [87], implementation of sequenced allelic ladders, validation of STR panels for forensic analysis, establishment of publicly available databases, collaborative efforts for the collection of population data, and proficiency and quality control testing (e. g. [88]).

In conclusion, the literature showed a relatively intense use of canine STR markers in the conservation, ecology, phylogeny and forensic fields in the last 15 years; however, inter-laboratory variability was considerable, in contrast with the high level of harmonization and standardization attained in a comparable period of human STR analysis. An integrated community where forensic and non-forensic researchers may converge needs to be established in order to further develop methodologies. In this perspective, it would be highly advantageous that major international societies such as the International Society of Animal Genetics (www. isag.org.uk) and the International Society of Forensic Genetics (www.isfg.org) collaborate in the development of guidelines for animal genotyping and specifically canine genotyping. These actions would certainly contribute to the emergence of a forensic community performing non-human analysis and the discussion of the particular challenges of a pioneering area.

\section{ACKNOWLEDGEMENTS}

The authors apologize to any authors whose studies we have unintentionally neglected to refer in this work and wish to acknowledge Leonor Gusmão and an anonymous reviewer for helpful suggestions on the manuscript. This work was supported by a research grant to BA (SFRH/BDE/15581/ 2006) and FP (SFRH/BPD/44637/2008) from Fundação para a Ciência e a Tecnologia. IPATIMUP is partially supported by Programa Operacional Ciência e Inovação 2010 (POCI 2010), VI Programa Quadro (2002-2006).

\section{REFERENCES}

[1] Muller, S.; Flekna, G.; Muller, M.; Brem, G. Use of canine microsatellite polymorphisms in forensic examinations. J. Hered., 1999, 90(1), 55-56.

[2] Shutler, G.G.; Gagnon, P.; Verret, G.; Kalyn, H.; Korkosh, S.; Johnston, E.; Halverson, J. Removal of a PCR inhibitor and resolu- 
tion of DNA STR types in mixed human-canine stains from a five year old case. J. Forensic Sci., 1999, 44(3), 623-626.

[3] Padar, Z.; Angyal, M.; Egyed, B.; Furedi, S.; Woller, J.; Zoldag, L.; Fekete, S. Canine microsatellite polymorphisms as the resolution of an illegal animal death case in a Hungarian zoological gardens. Int. J. Legal Med., 2001, 115(2), 79-81.

[4] Padar, Z.; Egyed, B.; Kontadakis, K.; Zoldag, L.; Fekete, S. Resolution of parentage in dogs by examination of microsatellites after death of putative sire: case report. Acta Vet. Hung., 2001, 49(3), 269-273

[5] Brauner, P.; Reshef, A.; Gorski, A. DNA profiling of trace evidence-mitigating evidence in a dog biting case. J. Forensic Sci., 2001, 46(5), 1232-1234.

[6] Padar, Z.; Egyed, B.; Kontadakis, K.; Furedi, S.; Woller, J.; Zoldag, L.; Fekete, S. Canine STR analyses in forensic practice. Observation of a possible mutation in a dog hair. Int. J. Legal Med., 2002, 116(5), 286-288.

[7] Halverson, J.L.; Basten, C. Forensic DNA identification of animalderived trace evidence: tools for linking victims and suspects. Croat. Med. J., 2005, 46(4), 598-605.

[8] Tsuji, A.; Ishiko, A.; Kimura, H.; Nurimoto, M.; Kudo, K.; Ikeda, $\mathrm{N}$. Unusual death of a baby: a dog attack and confirmation using human and canine STRs. Int. J. Legal Med., 2008, 122(1), 59-62.

[9] Eichmann, C.; Berger, B.; Reinhold, M.; Lutz, M.; Parson, W. Canine-specific STR typing of saliva traces on dog bite wounds. Int. J. Legal Med., 2004, 118(6), 337-342.

[10] Ostrander, E.A.; Sprague, G.F., Jr.; Rine, J. Identification and characterization of dinucleotide repeat (CA)n markers for genetic mapping in dog. Genomics, 1993, 16(1), 207-213.

[11] Holmes, N.G.; Mellersh, C.S.; Humphreys, S.J.; Binns, M.M.; Holliman, A.; Curtis, R.; Sampson, J. Isolation and characterization of microsatellites from the canine genome. Anim. Genet., 1993, 24(4), 289-292.

[12] Mellersh, C.S.; Langston, A.A.; Acland, G.M.; Fleming, M.A.; Ray, K.; Wiegand, N.A.; Francisco, L.V.; Gibbs, M.; Aguirre, G.D.; Ostrander, E.A. A linkage map of the canine genome. Genomics, 1997, 46(3), 326-336.

[13] Werner, P.; Mellersh, C.S.; Raducha, M.G.; DeRose, S.; Acland, G.M.; Prociuk, U.; Wiegand, N.; Aguirre, G.D.; Henthorn, P.S.; Patterson, D.F.; Ostrander, E.A. Anchoring of canine linkage groups with chromosome-specific markers. Mamm. Genome, 1999, 10(8), 814-823.

[14] Vignaux, F.; Hitte, C.; Priat, C.; Chuat, J.C.; Andre, C.; Galibert, F. Construction and optimization of a dog whole-genome radiation hybrid panel. Mamm. Genome, 1999, 10(9), 888-894.

[15] Richman, M.; Mellersh, C.S.; Andre, C.; Galibert, F.; Ostrander, E.A. Characterization of a minimal screening set of 172 microsatellite markers for genome-wide screens of the canine genome. J. Biochem. Biophys. Methods, 2001, 47(1-2), 137-149.

[16] Breen, M.; Hitte, C.; Lorentzen, T.D.; Thomas, R.; Cadieu, E.; Sabacan, L.; Scott, A.; Evanno, G.; Parker, H.G.; Kirkness, E.F.; Hudson, R.; Guyon, R.; Mahairas, G.G.; Gelfenbeyn, B.; Fraser, C.M.; Andre, C.; Galibert, F.; Ostrander, E.A. An integrated 4249 marker FISH/RH map of the canine genome. BMC Genomics, 2004, 5 (1), 65.

[17] Sargan, D.R.; Aguirre-Hernandez, J.; Galibert, F.; Ostrander, E.A. An extended microsatellite set for linkage mapping in the domestic dog. J. Hered., 2007, 98(3), 221-231.

[18] Lingaas, F.; Sorensen, A.; Juneja, R.K.; Johansson, S.; Fredholm, M.; Wintero, A.K.; Sampson, J.; Mellersh, C.; Curzon, A.; Holmes, N.G.; Binns, M.M.; Dickens, H.F.; Ryder, E.J.; Gerlach, J.; Baumle, E.; Dolf, G. Towards construction of a canine linkage map: establishment of 16 linkage groups. Mamm. Genome, 1997, 8(3), 218-221.

[19] Zajc, I.; Mellersh, C.; Kelly, E.P.; Sampson, J. A new method of paternity testing for dogs, based on microsatellite sequences. Vet. Rec., 1994, 135(23), 545-547.

[20] Binns, M.M.; Holmes, N.G.; Marti, E.; Bowen, N. Dog parentage testing using canine microsatellites. J. Small Anim. Pract., 1995, 36(11), 493-497.

[21] Fredholm, M.; Wintero, A.K. Efficient resolution of parentage in dogs by amplification of microsatellites. Anim. Genet., 1996, 27(1), 19-23.

[22] Koskinen, M.T.; Bredbacka, P. A convenient and efficient microsatellite-based assay for resolving parentages in dogs. Anim. Genet., 1999, 30(2), 148-149.
[23] Ichikawa, Y.; Takagi, K.; Tsumagari, S.; Ishihama, K.; Morita, M.; Kanemaki, M.; Takeishi, M.; Takahashi, H. Canine parentage testing based on microsatellite polymorphisms. J. Vet. Med. Sci., 2001, 63(11), 1209-1213.

[24] DeNise, S.; Johnston, E.; Halverson, J.; Marshall, K.; Rosenfeld, D.; McKenna, S.; Sharp, T.; Edwards, J. Power of exclusion for parentage verification and probability of match for identity in American Kennel Club breeds using 17 canine microsatellite markers. Anim. Genet., 2004, 35(1), 14-17.

[25] Halverson, J.; Basten, C. A PCR multiplex and database for forensic DNA identification of dogs. J. Forensic Sci., 2005, 50(2), 352363.

[26] Gottelli, D.; Sillero-Zubiri, C.; Applebaum, G.D.; Roy, M.S.; Girman, D.J.; Garcia-Moreno, J.; Ostrander, E.A.; Wayne, R.K. Molecular genetics of the most endangered canid: the Ethiopian wolf Canis simensis. Mol. Ecol., 1994, 3(4), 301-312.

[27] Roy, M.S.; Girman, D.J.; Taylor, A.C.; Wayne, R.K. The use of museum specimens to reconstruct the genetic variability and relationships of extinct populations. Experientia, 1994, 50(6), 551-557.

[28] Lade, J.A.; Murray, N.D.; Marks, C.A.; Robinson, N.A. Microsatellite differentiation between Phillip Island and mainland Australian populations of the red fox Vulpes vulpes. Mol. Ecol., 1996, 5(1), 81-87.

[29] Fredholm, M.; Wintero, A.K. Variation of short tandem repeats within and between species belonging to the Canidae family. Mamm. Genome., 1995, 6(1), 11-18.

[30] Ellegren, H.; Savolainen, P.; Rosen, B. The genetical history of an isolated population of the endangered grey wolf Canis lupus: a study of nuclear and mitochondrial polymorphisms. Philos. Trans. R Soc. Lond. B Biol. Sci., 1996, 351(1348), 1661-1669.

[31] Zajc, I.; Mellersh, C.S.; Sampson, J. Variability of canine microsatellites within and between different dog breeds. Mamm. Genome., 1997, 8(3), 182-185.

[32] Zajc, I.; Sampson, J. Utility of canine microsatellites in revealing the relationships of pure bred dogs. J. Hered., 1999, 90(1), 104107.

[33] Kim, K.S.; Tanabe, Y.; Park, C.K.; Ha, J.H. Genetic variability in East Asian dogs using microsatellite loci analysis. J. Hered., 2001, 92(5), 398-403.

[34] Irion, D.N.; Schaffer, A.L.; Famula, T.R.; Eggleston, M.L.; Hughes, S.S.; Pedersen, N.C. Analysis of genetic variation in 28 dog breed populations with 100 microsatellite markers. J. Hered., 2003, 94(1), 81-87.

[35] Lupke, L.; Distl, O., Microsatellite marker analysis of the genetic variability in Hanoverian Hounds. J. Anim. Breed. Genet., 2005, 122(2), 131-139.

[36] Irion, D.N.; Schaffer, A.L.; Grant, S.; Wilton, A.N.; Pedersen, N.C. Genetic variation analysis of the Bali street dog using microsatellites. BMC Genet., 2005, 6(1), 6.

[37] Puja, I.K.; Irion, D.N.; Schaffer, A.L.; Pedersen, N.C. The Kintamani dog: genetic profile of an emerging breed from Bali, Indonesia. J. Hered., 2005, 96(7), 854-859.

[38] Oishi, N.; Maeda, M.; Makimura, K.; Sawaguchi, T.; Hayashiya, M.; Kubo, T.; Kano, R.; Hasegawa, A.; Kasahara, M. Microsatellite polymorphism in Japanese mongrel dogs. J. Vet. Med. Sci., 2005, 67(10), 1055-1057.

[39] Schrameyer, T.; Dekomien, G.; Pasternack, S.M.; Reinartz, B.S.; Santos, E.J.; Epplen, J.T. Long- and short-haired Weimaraner dogs represent two populations of one breed. Electrophoresis, 2005, 26(9), 1668-1672.

[40] Bjornerfeldt, S.; Hailer, F.; Nord, M.; Vila, C. Assortative mating and fragmentation within dog breeds. BMC Evol. Biol., 2008, 8, 28.

[41] Leroy, G.; Verrier, E.; Meriaux, J.C.; Rognon, X. Genetic diversity of dog breeds: within-breed diversity comparing genealogical and molecular data. Anim. Genet., 2009, 40(3), 323-332.

[42] Leroy, G.; Verrier, E.; Meriaux, J.C.; Rognon, X. Genetic diversity of dog breeds: between-breed diversity, breed assignation and conservation approaches. Anim. Genet., 2009, 40(3), 333-343.

[43] Sundqvist, A.K.; Bjornerfeldt, S.; Leonard, J.A.; Hailer, F.; Hedhammar, A.; Ellegren, H.; Vila, C. Unequal contribution of sexes in the origin of dog breeds. Genetics, 2006, 172(2), 11211128 .

[44] Morera, L.; Barba, C.J.; Garrido, J.J.; Barbancho, M.; de Andres, D.F. Genetic variation detected by microsatellites in five Spanish dog breeds. J. Hered., 1999, 90(6), 654-656. 
[45] Wilton, A.N.; Steward, D.J.; Zafiris, K. Microsatellite variation in the Australian dingo. J. Hered., 1999, 90(1), 108-111.

[46] Koskinen, M.T.; Bredbacka, P. Assessment of the population structure of five Finnish dog breeds with microsatellites. Anim. Genet., 2000, 31(5), 310-317.

[47] Altet, L., Francino, O., Sanchez, A. Microsatellite polymorphism in closely related dogs. J. Hered., 2001, 92(3), 276-279.

[48] Vila, C.; Sundqvist, A.K.; Flagstad, O.; Seddon, J.; Bjornerfeldt, S.; Kojola, I.; Casulli, A.; Sand, H.; Wabakken, P.; Ellegren, H. Rescue of a severely bottlenecked wolf(Canis lupus) population by a single immigrant. Proc. Biol. Sci., 2003, 270(1510), 91-97.

[49] Lucchini, V.; Fabbri, E.; Marucco, F.; Ricci, S.; Boitani, L.; Randi, E. Noninvasive molecular tracking of colonizing wolf(Canis lupus) packs in the western Italian Alps. Mol. Ecol., 2002, 11(5), 857-868.

[50] Creel, S.; Spong, G.; Sands, J.L.; Rotella, J.; Zeigle, J.; Joe, L.; Murphy, K.M.; Smith, D. Population size estimation in Yellowstone wolves with error-prone noninvasive microsatellite genotypes. Mol. Ecol., 2003, 12(7), 2003-2009.

[51] Flagstad, O.; Walker, C.W.; Vila, C.; Sundqvist, A.K.; Fernholm, B.; Hufthammer, A.K.; Wiig, O.; Koyola, I.; Ellegren, H. Two centuries of the Scandinavian wolf population: patterns of genetic variability and migration during an era of dramatic decline. Mol. Ecol., 2003, 12(4), 869-880.

[52] Lucchini, V.; Galov, A.; Randi, E. Evidence of genetic distinction and long-term population decline in wolves(Canis lupus) in the Italian Apennines. Mol. Ecol., 2004, 13(3), 523-536.

[53] Weckworth, B.V.; Talbot, S.; Sage, G.K.; Person, D.K.; Cook, J. A signal for independent coastal and continental histories among North American wolves. Mol. Ecol., 2005, 14(4), 917-931.

[54] Aspi, J.; Roininen, E.; Ruokonen, M.; Kojola, I.; Vila, C. Genetic diversity, population structure, effective population size and demographic history of the Finnish wolf population. Mol. Ecol., 2006, 15(6), 1561-1576.

[55] Ólafsdóttir, G.A.; Kristjánsson, T. Correlated pedigree and molecular estimates of inbreeding and their ability to detect inbreeding depression in the Icelandic sheepdog, a recently bottlenecked population of domestic dogs. Conserv. Genet., 2008, 9, 1639-1641.

[56] Parra, D.; Mendez, S.; Canon, J.; Dunner, S. Genetic differentiation in pointing dog breeds inferred from microsatellites and mitochondrial DNA sequence. Anim. Genet., 2008, 39(1), 1-7.

[57] Vonholdt, B.M.; Stahler, D.R.; Smith, D.W.; Earl, D.A.; Pollinger, J.P.; Wayne, R.K. The genealogy and genetic viability of reintroduced Yellowstone grey wolves. Mol. Ecol., 2008, 17(1), 252274

[58] Pires, A.E.; Amorim, I. R.; Ginja, C.; Gomes, M.; Godinho, I.; Simoes, F.; Oom, M.; Petrucci-Fonseca, F.; Matos, J.; Bruford, M.W. Molecular structure in peripheral dog breeds: Portuguese native breeds as a case study. Anim. Genet., 2009, 40(4), 383-392.

[59] Dolf, G.; Schlapfer, J.; Gaillard, C.; Randi, E.; Lucchini, V.; Breitenmoser, U.; Stahlberger-Saitbekova, N. Differentiation of the Italian wolf and the domestic dog based on microsatellite analysis. Genet. Sel. Evol., 2000, 32(5), 533-541.

[60] Randi, E., Lucchini, V. Detecting rare introgression of domestic dog genes into wild wolf(Canis lupus) populations by Bayesian admixture analyses of microsatellite variation. Conserv. Genet., 2002, 3, 31-45.

[61] Andersone, Z.; Lucchini, V.; Randi, E.; Ozolins, J. Hybridisation between wolves and dogs in Latvia as documented using mitochondrial and microsatellite DNA markers. Mamm. Biol., 2002, 67, 79-90.

[62] Vila, C.; Walker, C.; Sundqvist, A.K.; Flagstad, O.; Andersone, Z.; Casulli, A.; Kojola, I.; Valdmann, H.; Halverson, J.; Ellegren, H. Combined use of maternal, paternal and bi-parental genetic markers for the identification of wolf-dog hybrids. Heredity, 2003, 90(1), 17-24.

[63] Verardi, A.; Lucchini, V.; Randi, E. Detecting introgressive hybridization between free-ranging domestic dogs and wild wolves(Canis lupus) by admixture linkage disequilibrium analysis. Mol. Ecol., 2006, 15(10), 2845-2855.

[64] Adams, J.R.; Lucash, C.; Schutte, L.; Waits, L.P. Locating hybrid individuals in the red wolf(Canis rufus) experimental population area using a spatially targeted sampling strategy and faecal DNA genotyping. Mol. Ecol., 2007, 16(9), 1823-1834.

[65] Wheeldon, T.; White, B.N. Genetic analysis of historic western Great Lakes region wolf samples reveals early Canis lupus/lycaon hybridization. Biol. Lett., 2009, 5(1), 101-104.
[66] Roy, M.S.; Geffen, E.; Smith, D.; Ostrander, E.A.; Wayne, R.K. Patterns of differentiation and hybridization in North American wolflike canids, revealed by analysis of microsatellite loci. Mol. Biol. Evol., 1994, $11(4)$, 553-5570.

[67] Sacks, B.N.; Brown, S.K.; Ernest, H.B. Population structure of California coyotes corresponds to habitat-specific breaks and illuminates species history. Mol. Ecol., 2004, 13(5), 1265-1275.

[68] Koskinen, M.T. Individual assignment using microsatellite DNA reveals unambiguous breed identification in the domestic dog. Anim. Genet., 2003, 34(4), 297-301.

[69] Parker, H.G.; Kim, L.V.; Sutter, N.B.; Carlson, S.; Lorentzen, T.D.; Malek, T.B.; Johnson, G.S.; DeFrance, H.B.; Ostrander, E.A.; Kruglyak, L. Genetic structure of the purebred domestic dog. Science, 2004, 304(5674), 1160-1164.

[70] Musiani, M.; Leonard, J.A.; Cluff, H.D.; Gates, C.C.; Mariani, S.; Paquet, P.C.; Vila, C.; Wayne, R.K. Differentiation of tundra/taiga and boreal coniferous forest wolves: genetics, coat colour and association with migratory caribou. Mol. Ecol., 2007, 16(19), 41494170.

[71] Veit-Kensch, C.E.; Medugorac, I.; Jedrzejewski, W.; Bunevich, A.N.; Foerster, M. A heuristic two-dimensional presentation of microsatellite-based data applied to dogs and wolves. Genet. Sel. Evol., 2007, 39(4), 447-463.

[72] Sundqvist, A.-K., Ellegren, H., Vilà, C., Wolf or dog? Genetic identification of predators from saliva collected around bite wounds of prey. Conserv. Genet., 2008, 9, 1275-1279.

[73] Kanthaswamy, S.; Tom, B.K.; Mattila, A.M.; Johnston, E.; Dayton, M.; Kinaga, J.; Joy-Alise Erickson, B.; Halverson, J.; Fantin, D.; Denise, S.; Kou, A.; Malladi, V.; Satkoski, J.; Budowle, B.; Glenn Smith, D.; Koskinen, M.T. Canine population data generated from a multiplex STR kit for use in forensic casework. J. Forensic Sci. 2009, 54(4), 829-840.

[74] van Asch, B.; Alves, C.; Santos, L.; Pinheiro, R.; Pereira, L.; Gusmão, L.; Amorim, A. Genetic profiles and sex identification of found-dead wolves determined by the use of an 11-loci PCR multiplex Forensic. Sci. Int. Genet., 2010, 4(2), 68-72.

[75] Murgia, C.; Pritchard, J.K.; Kim, S.Y.; Fassati, A.; Weiss, R.A Clonal origin and evolution of a transmissible cancer. Cell, 2006, 126(3), 477-487.

[76] Rebbeck, C.A.; Thomas, R.; Breen, M.; Leroi, A.M.; Burt, A. Origins and evolution of a transmissible cancer. Evolution, 2009, 63(9), 2340-2349.

[77] Parker, H.G.; Kruglyak, L.; Ostrander, E.A. Molecular genetics: DNA analysis of a putative dog clone. Nature, 2006, 440(7081), E1-2.

[78] Evans, J.J.; Wictum, E.J.; Penedo, M.C.; Kanthaswamy, S. Realtime polymerase chain reaction quantification of canine DNA. $J$ Forensic Sci., 2007, 52(1), 93-96.

[79] Gill, P.; Kimpton, C.P.; Urquhart, A.; Oldroyd, N.; Millican, E.S.; Watson, S.K.; Downes, T.J. Automated short tandem repeat(STR) analysis in forensic casework-a strategy for the future. Electrophoresis, 1995, 16(9), 1543-1552.

[80] Butler, J. M. Genetics and genomics of core short tandem repeat loci used in human identity testing. J. Forensic Sci., 2006, 51(2), 253-265.

[81] van Asch, B.; Alves, C.; Gusmão, L.; Pereira, V.; Pereira, F.; Amorim, A. A new autosomal STR nineplex for canine identification and parentage testing. Electrophoresis, 2009, 30(2), 417-423.

[82] Hellmann, A.P.; Rohleder, U.; Eichmann, C.; Pfeiffer, I.; Parson, W.; Schleenbecker, U. A proposal for standardization in forensic canine DNA typing: allele nomenclature of six canine-specific STR loci. J. Forensic Sci., 2006, 51(2), 274-281.

[83] Eichmann, C.; Berger, B.; Steinlechner, M.; Parson, W. Estimating the probability of identity in a random dog population using 15 highly polymorphic canine STR markers. Forensic Sci. Int., 2005, 151(1), 37-44.

[84] Eichmann, C.; Berger, B.; Parson, W. A proposed nomenclature for 15 canine-specific polymorphic STR loci for forensic purposes. Int. J. Legal Med., 2004, $118(5), 249-266$.

[85] Dayton, M.; Koskinen, M.T.; Tom, B.K.; Mattila, A.M.; Johnston, E.; Halverson, J.; Fantin, D.; DeNise, S.; Budowle, B.; Smith, D.G.; Kanthaswamy, S. Developmental validation of short tandem repeat reagent kit for forensic DNA profiling of canine biological material. Croat. Med. J., 2009, 50(3), 268-285.

[86] Budowle, B.; Garofano, P.; Hellman, A.; Ketchum, M.; Kanthaswamy, S.; Parson, W.; van Haeringen, W.; Fain, S.; Broad, T. Rec- 
ommendations for animal DNA forensic and identity testing. Int. J. Legal Med., 2005, 119(5), 295-302.

[87] Bär, W.; Brinkmann, B.; Budowle, B.; Carracedo, A.; Gill, P.; Lincoln, P.; Mayr, W.; Olaisen, B. Further report of the DNA Commission of the ISFH regarding the use of short tandem repeat systems. Int. J. Legal Med., 1997, 10, 175-176.

[88] van Asch, B.; Albarran, C., Alonso, A.; Angulo, R.; Alves, C.; Betancor, E.; Catanesi, C.; Corach, D.; Crespillo, M.; Doutremepuich, C.; Estonba, A.; Fernandes, A.T.; Fernandez, E.; Garcia,
A.M.; Garcia, M.A.; Gilardi, P.; Gonçalves, R.; Hernández, A.; Lima, G.; Nascimento, E.; Pancorbo, M.M.; Parra, D.; Pinheiro, M.F.; Prat, E.; Puente, J.; Ramírez, J. L.; Rendo, F.; Rey, I.; Di Rocco, F.; Rodríguez, A.; Sala, A.; J., S.; Sanchez, J. J.; Solá, D.; Silva, S.; Pestano, J. J.; Amorim, A. Forensic analysis of $\operatorname{dog}$ (Canis lupus familiaris) mitochondrial DNA sequences: An interlaboratory study of the GEP-ISFG working group. Forensic Sci. Int. Genet., 2009, 4(1), 49-54.

(C) van Asch and Pereira; Licensee Bentham Open.

This is an open access article licensed under the terms of the Creative Commons Attribution Non-Commercial License (http://creativecommons.org/licenses/by-nc/3.0/) which permits unrestricted, non-commercial use, distribution and reproduction in any medium, provided the work is properly cited. 